\title{
Hand Tuberculosis: a Common Disease at an Uncommon Site
}

\author{
Sushrut Tendulkar ${ }^{1} \cdot$ Shashikala Shivaprakash ${ }^{2} \cdot$ Bhupendra Gandhi $^{3} \cdot$ Paresh Jain $^{1}$
}

Received: 17 March 2020 / Accepted: 24 April 2020 / Published online: 10 May 2020

(C) The Author(s) 2020

\begin{abstract}
Tuberculosis (TB) is one of the major health problems in developing countries. India has the highest TB burden with approximately 27\% of global TB [6]. (India TB Report 2018 Revised National TB Control Programme (2018)). The most common form of tuberculosis constitutes pulmonary tuberculosis. Among extra pulmonary tuberculosis, the musculoskeletal tuberculosis accounts for about 10-15\% cases (Mohd Altaf Mir, Imran Ahmad, Mihd Yaseen (2016) World J Plast Surg 5(3):313-318). Hand involvement is seen in $10 \%$ of patients with musculoskeletal disease. There has been recent interest in tuberculosis of the hand because of a rising incidence owing to increasing numbers of immigration, an aging population, and immunosuppressed people including affected patients with human immunodeficiency virus [3,7] (Centre for Disease Control (1995) MMWR 14:1-16), Al-Qattan MM, AlNamla A, Al-Thunayan A, Al-Omawi M (2011) J Hand Surg 36:1413-1422). Tuberculous tenosynovial disease (TBTS) is the most common presentation of hand tuberculosis. In the hand, the flexor tendon sheath and radio-ulnar bursae are the most common sites of tenosynovitis. Tuberculosis of hand is more commonly seen in the dominant hand of the male population (Al-Qattan MM, AlNamla A, Al-Thunayan A, Al-Omawi M (2011) J Hand Surg 36:1413-1422). Here, we present a case of TBTS affecting extensor compartment of dominant hand in a post renal transplant immunosuppressed individual.
\end{abstract}

Keywords Hand tuberculosis $\cdot$ Tenosynovitis $\cdot$ Immunocompromised $\cdot$ Transplant

\section{Case Report}

A 33-year-old male, renal allograft recipient since 5 years, presented with gradually increasing painless swelling over dorsum of right hand since 2 months. Since 7 days, he developed pain over the swelling with low grade fever.

Patient was immunosuppressed with mycophenolate and prednisolone. He had tuberculous peritonitis 3 years back which was treated with antitubercular treatment for 9 months.

Clinical examination revealed $5 \times 5 \mathrm{~cm}$ soft, tender swelling over dorsum of right hand with overlying redness, increased local warmth and positive fluctuation. The range of

Sushrut Tendulkar

sushrut10dulkar@gmail.com

1 Department of Surgery and Allied, Sir H.N. Reliance Foundation Hospital and Research Centre, Mumbai, India

2 Department of Laboratory Medicine, Sir H.N. Reliance Foundation Hospital and Research Centre, Mumbai, India

3 Department of Renal Sciences, Sir H.N. Reliance Foundation Hospital and Research Centre, Mumbai, India motion for wrist joint was moderately restricted while that for metacarpophalangeal (MCP) joints was severely limited.

Hemogram showed neutrophilic leukocytosis. In view of acute onset inflammatory findings, a diagnosis of acute pyogenic abscess over dorsum of right hand was made. Patient underwent incision and drainage of the abscess, $75 \mathrm{ml}$ frank pus, drained. The extensor tendon sheaths and muscles were found to be inflamed and edematous. On squeezing along the tendon of extensor profundus, near the wrist joint, pus was oozing out. Infected tendon sheath was excised. Thorough wash was given and wound kept open for healing by secondary intention.

Post-operative recovery was uneventful. He was recommended regular dressing and active as well as passive physiotherapy of wrist and phalangeal joint. The smear examination revealed acid fast bacilli, and Mycobacterium tuberculosis (MTB) complex was isolated by MGIT automated culture method. The aerobic bacterial culture was negative.

Magnetic resonance imaging (MRI) hand was done which revealed extensive diffuse subcutaneous, intramuscular edema, and inflammation along the palmer and dorsum of hand and wrist joint, with marked extensor tenosynovitis without bony involvement. 
Non-rifampicin based regimen was started, because of risk of drug interactions, which included isoniazid, moxifloxacin, pyrazinamide, and ethambutol.

On 6 months of follow up with regular dressing and active physiotherapy, wound healed completely with full and painless range of motion at wrist and MCP joint. Figures 1 and 2

\section{Discussion}

TB of the hand is classified according to the type of tissue involved: Cutaneous TB, tuberculous tenosynovitis, bursitis, osteomyelitis, arthritis, and tuberculous hypersensitivity reactions [1]. Tenosynovial involvement is the most common presentation of $\mathrm{TB}$ of the hand. Painful swelling and limitation of movement are classic symptoms, as also seen in our case $[1,2]$.

TBTS of hand may occur after hematogenous spread of mycobacterium from lungs, lymphatic tissue, and other viscera. Our patient had previous history of tuberculous peritonitis and a sequel of an old infection in the chest on chest X-ray [3]. TB hand is difficult to diagnose due to absence of specific symptoms and rarity of presentation. MRI is of great help in ruling out osseous involvement. Preoperative MRI is not done in our case as the diagnosis of pyogenic abscess was clinically obvious and timely incision and drainage of the abscess was needed.

For unknown reasons, the flexor side is more commonly involved than the extensor side; unlike in our case where extensor compartment was involved. There are 3 stages of TBTS, viz., hygromatous, serofibrinous, and fungoid. In first stage, the tendon is replaced by vascular granulation tissue. In second stage, the sheath is obliterated by fibrous tissue, fluid is confined within the sheath, and rice bodies may appear due to caseation. Frank pus with minimal caseation was noted in the abscess cavity, in our patient. They may present with ruptured tendon in third stage of the disease [1-4]. When healing by fibrous tissue formation fails to curtail the pathologic process, extensive caseation and granulation occur, similar to our case,

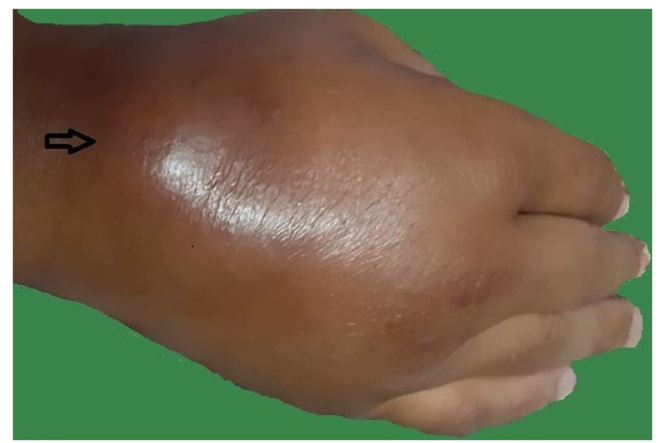

Fig. 1 Swelling over dorsum with positive fluctuation and s/o local inflammation

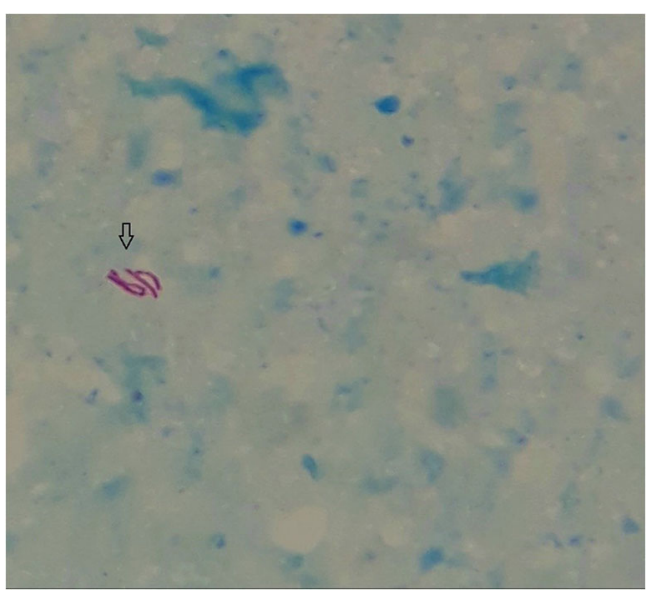

Fig. 2 Ziehl-Neelsen $(\mathrm{ZN})$ stain: arrow mark showing long, slender acid fast bacilli in $\times 100$

which may lead to sinus formation and superimposed secondary infection [3]. Rice bodies represent fibrinous masses (tubercles) which are present in 50\% of cases [5]. Their presence stimulates synovial proliferation and promotes recurrences. Apart from tuberculous tenosynovitis, rice bodies can be seen in other diseases like rheumatoid arthritis, systemic lupus erythematosus [1].

TBTS has several classic presentations; important ones are compound palmar ganglion, sausage digit, and carpal tunnel syndrome $[1,4]$. Some of the uncommon manifestations includes mid-palmar abscess, flexor TBTS, and occasionally extensor TBTS, as seen in our case.

Treatment of TBTS includes incision and drainage of abscess and synovectomy followed by antituberculous treatment. Hand physiotherapy, which wasn't considered by many of the previous studies, plays an important role in regaining full range of motion of the affected joints, as clearly seen in our case.

\section{Conclusion}

TBTS is difficult to diagnose due to absence of specific symptoms, and pyogenic abscess becomes the most common differential diagnoses. There is paucity of data addressing guidelines for the management of TBTS. Hence, in majority of cases the diagnosis of TBTS gets delayed and becomes evident after microbiological report.

Early incision and drainage of abscess with excision of the infected tissues combined with antituberculous multidrug therapy is the treatment of choice. Hand physiotherapy plays pivotal role in early recovery and better functional outcome.

\section{Compliance with Ethical Standards}

Conflict of Interest The authors declare that they have no conflict of interest. 
Open Access This article is licensed under a Creative Commons Attribution 4.0 International License, which permits use, sharing, adaptation, distribution and reproduction in any medium or format, as long as you give appropriate credit to the original author(s) and the source, provide a link to the Creative Commons licence, and indicate if changes were made. The images or other third party material in this article are included in the article's Creative Commons licence, unless indicated otherwise in a credit line to the material. If material is not included in the article's Creative Commons licence and your intended use is not permitted by statutory regulation or exceeds the permitted use, you will need to obtain permission directly from the copyright holder. To view a copy of this licence, visit http://creativecommons.org/licenses/by/4.0/.

\section{References}

1. Sbai MA, Benzarti S, Msek H, Boussen M, Khorbi A (2016) Pseudotumoral form of soft-tissue tuberculosis of the wrist. Int $\mathrm{J}$ Mycobacteriol 5:99-101
2. Shareef AJ, Sreehari CK, Bhat S, Nithin S (2015) Extensors tenosynovitis of wrist with rupture of extensor digitorum: rare presentation of tuberculosis. Int Surg J 2(3):398-401

3. Mir MA, Ahmad I, Yaseen M (2016) Primary tuberculosis of hand soft tissue. World J Plast Surg 5(3):313-318

4. Al-Qattan MM, Al-Namla A, Al-Thunayan A, Al-Omawi M (2011) Tuberculosis of the hand. J Hand Surg 36:1413-1422

5. Hoffman KA et al (1996) Tuberculosis tenosynovitis of the flexor tendons of the wrist: MR imaging with pathologic correlation. Skelet Radiol 25:186-188

6. India TB Report 2018 Revised National TB Control Programme (2018) Annual Status Report. New Delhi: Central TB Division, Directorate General of Health Services

7. Centre for Disease Control (1995) Essential components of a tuberculosis prevention and control program: Recommendations of the Advisory Council for the elimination of tuberculosis. MMWR 14: 1-16

Publisher's Note Springer Nature remains neutral with regard to jurisdictional claims in published maps and institutional affiliations. 